\title{
Sex ratio in offspring of those affected by dioxin and dioxin-like compounds: the Yusho, Seveso, and Yucheng incidents
}

\author{
T Yoshimura, S Kaneko, H Hayabuchi
}

\begin{abstract}
Sex ratios in the offspring of those affected by dioxins or dioxin-like compounds have been reported from Seveso, Italy and Yucheng, Taiwan. The sex ratio of live births in Yusho, Japan after a similar accidental massive exposure to polychlorinated biphenyls (PCBs) and polychlorinated dibenzofurans (PCDFs) in 1968 are reviewed. Data on all births among parents exposed to the compounds from 1968 to 1977 in Fukuoka and a region of Nagasaki, the two areas affected, are reported. In total there were 85 live births in those regions. The sex ratio was not significantly different from normal (0.513). To evaluate hormonal disrupting activity or effects on reproductive outcome by PCBs and PCDFs, a further investigation of sex in offspring of the Yusho victims, especially offspring of those who were younger than 19 years of age at the time of the Yusho incident, is needed.

(Occup Environ Med 2001;58:540-541)
\end{abstract}

Keywords: sex ratio; benzofurans; polychlorinated biphenyls

Public concern about the hazardous effects of dioxin and dioxin-like compounds in humans is increasing. Some of these compounds are thought to affect reproductive outcomes such as the male to female ratio of offspring through disrupting hormones. The number of female live births significantly exceeded that of male live births several years after the incident in Seveso, Italy, where 2,3,7,8-tetrachlorodibenzo- $p$-dioxin (TCDD) was the main compound causing the

Table 1 Number and sex of live births that occurred in Nagasaki and Fukuoka before and after the incident

\begin{tabular}{|c|c|c|c|c|c|c|c|c|c|}
\hline & \multicolumn{3}{|c|}{ Fukuoka } & \multicolumn{3}{|c|}{ Nagasaki } & \multicolumn{3}{|l|}{ Total } \\
\hline & Boys & Girls & $p$ Value & Boys & Girls & $p$ Value & Boys & Girls & $p$ Value \\
\hline \multicolumn{10}{|l|}{ Before the incident: } \\
\hline $\begin{array}{l}\text { January 1967-January } 1968 \\
\text { After the incident: }\end{array}$ & 13 & 10 & After the incident: & 3 & 5 & 0.497 & 16 & 15 & 1.000 \\
\hline February 1968-December 1968 & 10 & 5 & 0.304 & 1 & 5 & 0.116 & 11 & 10 & 1.000 \\
\hline January 1969-December 1971 & 18 & 10 & 0.129 & 6 & 6 & 1.000 & 24 & 16 & 0.343 \\
\hline January 1972-December 1977 & 14 & 10 & 0.545 & - & - & - & - & - & \\
\hline Total (after the incident) & 42 & 25 & 0.067 & 7 & 11 & 0.349 & 49 & 36 & 0.278 \\
\hline
\end{tabular}

Statistical tests were conducted by applying binomial probability tests using the probability of the birth of a boy of 0.513 obtained from statistics of Japan, 1967.

exposure. ${ }^{12}$ In the incident in Yucheng, Taiwan, where the main exposure was to polychlorinated biphenyls (PCBs) and polychlorinated dibenzofurans (PCDFs), no effect on the sex ratio of live births was found. ${ }^{3}$

The incident in Yusho, western Japan in 1968 was a massive accidental exposure to PCBs and PCDFs caused by ingestion of a commercial brand of rice oil contaminated with these chemicals. As a result, about 1800 patients had several clinical symptoms such as acneiform eruptions, pigmentation of the skin, nails, and conjunctivas, increased discharge from the eyes, and numbness of the limbs. ${ }^{4}$ For several years after the incident, all births that occurred among parents, at least one of whom was exposed to those compounds in the two regions affected, have been identified to evaluate an effect of the parental exposure to PCBs and PCDFs on sex ratio of newborn infants. In this report, we review the data on sex ratios from the Yusho incident.

\section{Methods}

All births that occurred among parents, at least one of whom was affected by the incident in Fukuoka and a region of Nagasaki were reviewed from 1967 to 1977 to find whether the consumption of rice oil contaminated with dioxin-like compounds had any effect on the sex ratio. To test the null hypothesis that the probability of a male live birth in affected parents is equal to that in the general population (0.513), ${ }^{5}$ two sided binomial probability tests were conducted with the STATA statistical package (version 7.0). ${ }^{6}$

Japan

T Yoshimura

S Kaneko

Department of Nutrition and Health Science, Fukuoka

Women's University, Fukuoka, Japan

H Hayabuchi

Correspondence to:

Dr T Yoshimura

yoshitk@med.uoeh-u.ac.jp

Accepted 17 April 2001 


\section{Results}

There were 67 live births in Fukuoka after the incident from February 1968 to December 1977 and 18 live births in the region of Nagasaki from February 1968 to December 1971 (table 1). The probability of having a male live birth was not significantly different from that of general population. In Fukuoka, the number of live boys born after the incident exceeded girls (42 $v$ 25), but the difference was not significant. In Nagasaki, the probability of a live boy being born did not significantly increase or decrease in any period examined, although there were more live girls born in the 11 months immediately after the incident (five girls $v$ one boy).

\section{Discussion}

We could not find any excess of births of girls over boys in the Yusho incident, a different result from that reported after the Seveso incident, ${ }^{12}$ but similar to that found in the Yucheng incident in Taiwan. ${ }^{3}$ The main difference between the Seveso and the Yusho and Yucheng incidents is the make up of the compounds exposed to. In Seveso, TCDD was the main compound causing exposure, but it was PCBs and PCDFs in Yusho and Yucheng; TCDD was not found in the contaminated rice oil. ${ }^{7}$ Therefore, there could be different mechanisms of action between TCDD and PCBs or PCDFs on the sex ratio that could explain the different results in these incidents. Mocarelli et al inferred from the Seveso incident that TCDD induces epididymal impairments or acts on an Ah receptor which is thought to mediate the effect of TCDD to change the sex ratio. ${ }^{2}$

In Seveso, exposure to TCDD before or during puberty in males was a predictive factor for producing more female offspring in later life. ${ }^{2}$ Our study period was too brief to allow us to follow up births to those who were exposed to PCBs or PCDFs before or during puberty. To clarify the effect of dioxin and dioxin-like compounds on young males with regard to their future offspring, a further investigation of sex of their offspring needs to be carried out for the Yusho victims, especially those who were younger than 19 years of age at the time of the incident.

This work was partly supported by a grant in aid for scientific research from the Ministry of Health and Welfare, Japan.

1 Mocarelli P, Brambilla P, Gerthoux PM, et al. Change in sex ratio with exposure to dioxin. Lancet 1996;348:409.

2 Mocarelli P, Gerthoux PM, Ferrari E, et al. Paternal concentrations of dioxin and sex ratio of offspring. Lancet 2000;355:1858-63.

3 Rogan WJ, Gladen BC, Guo YL, et al. Sex ratio after exposure to dioxin-like chemicals in Taiwan. Lancet 1999;353: 206-7.

4 Kuratsune $M$. Outlines of Yusho. In: Kuratsune M, Yoshimura H, Hori Y, et al., eds. Yusho: a human disaster caused by PCBs and related compounds. Fukuoka: Kyushu University Press, 1996:1-6.

5 Health and Welfare Statistics Association, ed. Kokumin-eiseino doukou. Tokyo: Health and Welfare Statistics Association, 1967.

6 Stata Corp. Stata reference manual release 7. Texas: Stata Press, 2001.

7 Masuda Y. Causal agents of Yusho. In: Kuratsune M, Yoshimura H, Hori Y, et al., eds. Yusho: a human disaster caused by PCBs and related compounds. Fukuoka: Kyush University Press, 1996:47-80.

\footnotetext{
Open reviewing

Many journals, including the BMJ, have moved to a system of open reviewing, whereby authors know the names of reviewers of their papers. Research has shown that named reviews, although not of better quality than anonymous reviews, are not of worse quality either. Therefore in the interests of transparency, it seems fair to let authors know who has reviewed their paper. At Occupational and Environmental Medicine we have considered the issue carefully. There are some concerns that reviewers, especially those who are more junior, might feel intimidated and not wish to make negative comments about papers submitted by senior people in the field. On the other hand, some reviewers might hide behind the cloak of anonymity to make unfair criticisms so as to reduce the chances of publication by rivals. We have decided to introduce initially a system of open reviewing if the reviewers agree explicitly. So when a reviewer is sent a paper, he or she is asked to indicate whether we can disclose their name or not when sending the authors their comments. We will be monitoring this to see how many of our reviewers are happy to be named. If it is most of them, we will move to a system of open reviewing as the norm, with a possible "opt out" clause for reviewers.
} 